\title{
Shoring Up the Shaky Psychological Foundations of a Micro-Economic Model of Ideology: Adversarial Collaboration Solutions
}

\author{
Thomas H. Costello* \\ Emory University, Department of Psychology \\ Cory J. Clark \\ Phillip E. Tetlock \\ University of Pennsylvania, Department of Psychology
}

In press, Psychological Inquiry (Ed. W. Cunningham).

*Corresponding author: Thomas H. Costello, 36 Eagle Row, Department of Psychology, Emory University, Atlanta, GA, 30322. E-mail: thcostello1@gmail.com. 


\section{Shoring Up the Shaky Psychological Foundations of a Micro-Economic Model of Ideology: Adversarial Collaboration Solutions}

Phenomena at the nexus of ideology and psychology are typically viewed as complexly determined, implicating personality traits, cognitive styles and abilities, moral intuitions and cultural values, motivations for group belonging, social status and material resources, and an endless array of environmental trigger cues. Despite decades of theory-driven research seeking to distill these dispositional and situational "ingredients" into coherent psychopolitical portraits of activists - liberals, conservatives, libertarians, authoritarians, totalitarians - our theories of the "political mind" arguably remain immature (e.g., Fried, 2020). Indeed, vigorous and enduring controversies have long characterized the psychology of ideology literature, during which time proponents of competing theories have launched hundreds of studies and reviews at one another from their respective corners - perhaps to the detriment of progress in the field as a whole. Often these discussions manifest in commentaries where scholars inaccurately characterize their opponents' arguments, make false assumptions about what their opponent might have predicted in a given situation, and commit other violations of Rapaport's rules of argumentation (see Dennett, 2013, pp. 33-35). Although science thrives on criticism (Popper, 1940), in highpolitical-stakes literatures fraught with ambiguity, it becomes all too easy for competing camps to talk past one another, leaving us mired in seemingly perpetual controversy.

Our view here is that the "elective affinities" (Jost et al., 2009) account of ideological preferences (a central premise in Gries and colleagues' [this issue] otherwise adeptly executed micro-economic framework) is deeply flawed and grounded in a noisy and frequently contradictory empirical literature. If this were a typical commentary, our core critique of the target article might be that it assumes that our knowledge of belief systems, psychological needs, 
and the causal relations between them are, in effect, "solved"- - a proposition we see as false. We might argue that whether and to what extent psychological needs are meaningfully (let alone causally) related to broad-based ideological preferences has yet to be empirically established; the conceptual resonance between psychological characteristics and the need-fulfilling properties of belief systems is both dubious and beyond the ability of psychological science to quantify (in part because the complex evolution of belief systems outpaces present scientific knowledge); and discrete psychological mechanisms driving ideological preferences remain obscure. Hence, acquiring the psychometric capacity to test and apply the model would constitute a stunningly rapid scientific advance given the normal pace of progress in political psychology. We might conclude that a framework synthesizing microeconomics and political psychology strikes us as eminently sensible, but Gries and colleagues' mathematical formulation of the elective affinities model mainly serves to highlight the many stubborn, unresolved questions in this literature-and the answers are more elusive than the authors suppose.

Would this barrage of arguments persuade scholars who disagree with us? We would like to think so. More likely, however, our opponents would marshal persuasive counterarguments, charge us with misreading a veritable ocean of evidence supporting their perspective (e.g., multiple meta-analytic reviews have supported the elective affinities model), and perhaps conclude that we have fundamentally misunderstood what the science says (i.e., exactly what we have accused them of doing). At the end of the day, our perspectives will have moved further apart, not closer together - and the scholarly imbroglio surrounding the psychology of ideology would continue unimpeded.

Adversarial collaboration offers a means of breaking this vicious cycle by fostering consensus, rather than controversy. Such collaborations involve investigations that are planned, 
conducted, and analyzed by two or more disagreeing scholars. As such, the adversaries must collectively identify (a) their sources of disagreement and (b) appropriate, mutually agreeable tests to arbitrate between their competing perspectives. First described by Nobel Laureate, Daniel Kahneman, adversarial collaborations challenge scholars to (1) fairly characterize one another's positions; (2) work together to build and carry out investigations that they have agreed have the potential to change their minds; and (3) publish the results regardless of the outcome (Clark \& Tetlock, 2022; Mellers et al., 2001; Tetlock \& Mellers, 2011).

Hence, in the spirit of adversarial collaboration, we devote the remainder of this commentary to exploring our disagreements with Gries and colleagues with the goal of discovering common ground. We will use a series of thought experiments (concerning the elective affinities model) to facilitate this goal. Thought experiments are typically used by philosophers to arbitrate between competing assumptions by working through the logical consequences of changing certain aspects of one's argument to "construct a coherent model of the situation [one] is imagining" (Cooper, 2005, p. 337). Our hope is that, as a field, we can use thought experiments to identify and implement actual experiments (as adversarial collaborations) designed to resolve longstanding debates in political psychology (ideally, crucial experiments, which make one theory among a set of competitors stand out as far more probable; Bacon, 1620), thereby facilitating what Platt (1964) termed "strong inference." As we pose our series of thought experiments, we ask proponents and skeptics alike to consider whether and to what extent they would update their perspectives if the results of each proposed experiment conflicts with (vs. supports) their expectations.

\section{Theoretical Corroboration and Effect Sizes}


There have been several meta-analytic reviews of the associations between psychological needs and political ideology (e.g., Houck \& Conway, 2019; Jost et al., 2017a; Jost et al., 2017b; Van Hiel et al., 2016). It is uncontroversial to suggest that the results of a properly conducted meta-analysis allow for reasonably sound conclusions about the magnitude and direction of a relation between two constructs. Nevertheless, the implications of meta-analysis for weightier epistemic questions - such as the extent to which meta-analysis allows scholars to "discover the latent meaning of existing research literatures" (Hunter \& Schmidt, 2014, p. 22) or the core mechanisms underlying a trait or disorder-remain controversial, intersecting with philosophyof-science debates over the feasibility of confirming or disconfirming various classes of theories (Glass, 2015; Meehl, 1978) that are perhaps better addressed by constructing and evaluating formal models (cf. Roberts \& Pashler, 2000; see Rodgers, 2010)—as Gries and colleagues so deftly begin to do in their article.

Our view is Popperian: although meta-analytic effect size estimates alone are not sufficient to evaluate verisimilitude claims of theories, small or statistically negligible effects are enough to rule them out. Auspiciously for proponents of elective affinities, previous metaanalytic reviews of relations between psychological needs and political conservatism have not yielded null-effect sizes. Rather, they have yielded a wide range of effect size estimates that vary around a median estimate of roughly $r=.20$; e.g., Jost et al., 2017a; Jost et al., 2017b; Van Hiel et al., 2016). Putting aside the quality of these meta-analyses for the moment (see Malka et al., 2017), these findings suggest a moderate positive correlation between psychological needs for certainty and safety and political conservatism.

So, suppose, as our first thought experiment, that the "true" effect is much smaller (and a more comprehensive, peer-reviewed meta-analytic investigation backed up the claim). Although 
certain small effects can have profound real-world implications (Funder \& Ozer, 2019), one obstacle to interpreting the ideological asymmetries literature is that there is no established or consensual size of "difference" between the left and right that scholars consider meaningful (see Lakens et al., 2018). Statistical significance notwithstanding (Meehl, 1978), how different would the right and left have to be for us to conclude that they are, in fact, different? Or, put another way, how small (vs. large) would correlations/effect sizes between needs and conservatism have to fall (vs. grow) before we begin to lose confidence in the elective affinities model? How small (vs. large) would they have to be to jettison our theoretical conclusions entirely?

Given that the elective affinities model (and Gries and colleagues' model) implies causality, we posit that the criterion for accepting a meaningful effect should be relatively strict: Ideological asymmetries should be reasonably robust, not wobbling near zero. If we use Cohen's effect size benchmarks, intended to describe the meaningfulness of a result (e.g., a small effect size can only be detected via careful study whereas a medium effect size is visible to "the naked eye of a careful observer"), we would take $r=.10, r=.30$, and $r=.50$ to represent small, medium, and large effect sizes. Hence, we would begin to gain confidence in the elective affinities model as correlations approached a range of $r=.25$ to $r=.35$, and our confidence would increase dramatically as effect sizes approached $r=.40$. By the same token, effect sizes from $r=.05$ to $r=.15$ would support the possibility that the elective affinities model is of dubious practical value, and we would treat effect sizes below $r=.05$ as falsifying the model. Our own reading of the literature is that "true" effect sizes vary a lot with context (e.g., Houck \& Conway, 2019; Malka \& Soto, 2015; Tetlock et al., 1984; Tetlock, 1986) but will tend to cluster in the $r=.05$ to $r=.15$ range.

\section{Causal Evidence of Need-Ideology Relations}


In our view, the available evidence provides little direct support for the possibility that psychological needs cause ideology. Indeed, the evidence for ideological differences in psychological needs is virtually exclusively correlational, and efforts to establish causality have proven unsuccessful or mixed (for an exception that merits replication, see Block \& Block, 2006). Further, there seem to be three plausible/popular "causal stories," only the first of which supports the elective affinities model: (1) needs/traits cause ideology, (2) ideology causes needs/traits, and (3) an upstream process causes both ideology and needs/traits (e.g., genes or environment). Of course, it also possible that there is no meaningful statistical relation between psychological characteristics and belief systems.

Evidence is mixed across these possibilities. For instance, consider the few longitudinal studies of relations between personality traits and political conservatism. Most recently, Bakker and colleagues (in press) reported data from three longitudinal surveys in the Netherlands (11 years), Germany (5 years), and the U.S. (4 years), finding that openness and conscientiousness incrementally (e.g., $\beta s \sim .07)$ predict political conservatism, but also that political conservatism incrementally predicts openness and conscientiousness (with roughly the same effect sizes). This mutual pattern of prediction is consistent with possibilities 1 and 2, supporting electoral affinities while implying that "models depicting the one-way causal influence of personality traits on political preferences from cross-sectional data will be likely to overestimate this causal influence" (Bakker et al., in press, p. 27). Notably, the cross-lagged panel models used in Bakker et al. have been criticized for confounding within-person change with between-person stability (Hamaker, Kuiper, \& Grasman, 2015), thereby rendering sound interpretation difficult. Supporting this possibility, a large, nine-wave longitudinal examination of the relation between openness and conservatism in adults found no evidence that personality precedes - let alone 
causes - ideology, or vice versa, after disaggregating between-person stability from withinperson change (Osborne \& Sibley, 2020). This implies that a third variable may account for the relation between personality and politics (e.g., Ksiazkiewicz \& Friesen, 2018). In this light, we pose the following thought experiment: How would conclusions shift if openness/conscientiousness more strongly predicted political conservatism in longitudinal studies (e.g., $\beta$ s from .15 to .25)? What if the "true" effect sizes fell between $\beta=.01$ to .05 ? Would this be enough to undercut the conclusion that personality traits have a meaningful causal influence on political ideology?

One means of clarifying the trait-ideology causal pathway has emerged recently. Several interventions (including psychotherapy and a smartphone application) ostensibly change individuals' levels of self-reported personality traits (e.g., Roberts et al., 2017; Stieger et al., 2021), although notably these results do not seem to extend to openness (the trait most studied in relation to ideology) and are much smaller, and often non-significant, for observer reports. Nevertheless, the ability to manipulate personality traits raises an intriguing question for proponents of elective affinities: What if manipulating participants' personality traits leads to changes in political ideology? Our perspective, at least, is that such a finding would offer fairly clear evidence in support of the ideological asymmetries model — and as such, a similar study might be a suitable foundation for adversarial collaboration.

\section{Semantic Overlap}

Many political psychologists have highlighted the problematic extent to which semanticcontent overlap in measures of psychological and political constructs may bias findings towards ideological asymmetries (e.g., Malka et al., 2017; Reyna, 2017). Ostensibly empirical connections may merely be logical tautologies. For instance, in Jost et al.'s (2003) meta-analysis 
of the motivated social cognition model of ideology, the F (Fascism) Scale (Adorno et al., 1950), the Right-wing Authoritarianism Scale (Altemeyer, 1996), and the C (Conservatism) Scale (Wilson \& Patterson, 1968) comprise $60 \%$ of political conservatism measures examined in relation to needs for certainty. The F Scale (10\% of certainty effect sizes) is intended to assess "fascist receptivity at the personality level" (e.g., "Most of our social problems would be solved if we could somehow get rid of the immoral, crooked, and feebleminded people"). The Rightwing Authoritarianism Scale (12\% of effect sizes) assesses unquestioned reverence for authority, aggression towards outgroup members, and strict adherence to a set of socially conservative norms (e.g., "Our country desperately needs a mighty leader who will do what has to be done to destroy the radical new ways and sinfulness that are ruining us"). Finally, the C Scale (38\% of effect sizes) asks participants to indicate their support for "general attitudes concerning uncertainty avoidance" (Jost et al., 2003, p. 340), artistic movements that often involve ambiguity (e.g., jazz music, modernism), and specific social-political issues that carry authoritarian or prejudicial connotations (e.g., censorship, white superiority, church authority, women judges). Later meta-analyses reveal similar degrees of content overlap. For instance, Van Hiel, Onraet, and De Pauw (2010) investigated the relations between right-wing attitudes and behavioral measures of cognitive rigidity (i.e., excluding self-reports) in 124 samples involving 29,209 unique participants. The analysis operationalizes right-wing attitudes using measures of "authoritarianism, ethnocentrism, conservatism, and dogmatism" (p. 1773). Although these measures are sometimes strongly correlated with social conservatism, this measurement approach raises the specter of criterion contamination: it assumes the consequent and is akin to testing the law of thermal expansion with an experiment that measures temperature via a mercury thermometer (see Franklin et al., 1989). 
Less overt instances of content overlap are also worth mentioning. For instance, "I often visit art museums," a commonly used openness to experience item, may well be a sound indicator of openness among liberals, who tend to live in cities and, therefore, have access to many museums. Among conservatives, however, who tend to live in sparsely populated areas, this item may function relatively poorly (see also Charney, 2015). Further, several critics of the Symbolic Racism Scale have argued that many items confound value judgments about meritocracy and hard work with racism (e.g., "It's really a matter of some people not trying hard enough; if blacks would only try harder, they could be just as well off as whites"), such that individuals who believe that hard work usually leads to success (i.e., conservatives) will score artificially highly (Redding, 2001; Sniderman \& Tetlock, 1986). As another example of item bias due to ideological commitments, Stanovich and Toplak (2019) found that religious individuals respond differently than non-religious individuals to Actively Openminded Thinking (AOT) Scale items that include the word "belief." Individuals with strongly held religious views generally take "beliefs" to mean "religious beliefs," whereas non-religious individuals generally take "beliefs" to mean "opinions." After the offending items were removed, Stanovich and Toplak (2019) found that AOT-religiosity correlations were reduced from roughly $r=-.60$ to roughly $r=-.20$. Perhaps notably, several other oft-used measures in social and personality psychology frequently use the word 'belief” in a similar manner, including Altemeyer's (1996) DOG Scale, the most popular psychological measure of dogmatism, which does so in 6 of its 22 items.

These considerations suggest an additional thought experiment: If removing measures with semantic overlap between the predictor and outcome variables reduced previous metaanalytic estimates, how large (vs. small) would method artefacts due to semantic overlap have to 
be before we begin to lose (vs. gain) confidence in prior findings/meta-analyses concerning the elective affinities model? Relatedly, how small (vs. large) would effect sizes need to be for other measurement modalities (e.g., observer-reports, performance-based and behavioral instruments, ecological momentary assessment) before we begin to lose (vs. gain) confidence in the elective affinities model? Here, we draw on our previous ex ante estimate concerning correlations effects. Meta-analytic effect sizes (corrected for semantic overlap) from $r=.05$ to $r=.15$ would indicate that the elective affinities model is of dubious practical value, and effect sizes below $r=.05$ would gravely undercut the model.

\section{The Multidimensionality of Political Ideology}

Despite the popularity of the left vs. right political spectrum among researchers—one recent estimate suggested that it is used in $80 \%$ of political psychology studies (Claessens et al., 2020)—it is not clear that "liberalism" and "conservatism" are psychologically coherent categories. A noted by Gries and colleagues, a plethora of studies have found that the political spectrum can be decomposed into at least two conceptually and empirically distinct social and economic content dimensions (e.g., Claessens et al., 2020; Costello \& Lilienfeld, 2020; Duckitt \& Sibley, 2009; Federico \& Malka, 2018; Feldman \& Johnston, 2014), which may serve as a reasonably accurate taxonomy of the psychological structure of political ideology. Social and economic ideologies are not typically positively correlated outside certain Western democracies (Feldman \& Johnston, 2014). Indeed, a recent investigation using survey data from nearly 100 nations found that (a) economic and social attitudes rarely fall along a single left-right dimension and (b) right-wing social attitudes are, on aggregate, slightly positively correlated with left-wing economic attitudes (Malka et al., 2017), suggesting that social and economic ideology may not be aligned as elites often suppose absent top-down influences (Feldman, 2013). 
Nevertheless, Jost and colleagues $(2003,2017)$ have argued that all manner of conservative ideologies (i.e., social and economic) serve the psychological function of justifying and maintaining the legitimacy of the prevailing socio-cultural system, and that these system justification motives "are the 'glue' that holds left-right ideology...together" (Jost et al., 2013, p. 1) by promising certainty and safety. If both economic and social conservatism are indeed rooted in system justification, they should be similarly associated with psychological needs, which may not be true. Thus, we pose another thought experiment: How small (vs. large) would organic correlations between social and economic conservatism have to be before one loses (vs. gains) confidence in the belief that system justification motives underlie broad-based conservatism? How small (vs. large) would they have to be to jettison (vs. endorse) the proposition entirely?

A theory that accurately explains only one half of the phenomena it purports to explain seems to merit substantial revision. Given that economic conservatism is presumably just as "right-wing” as social conservatism, small or null correlations between social and economic ideology constitute a falsifying condition of the electoral affinities model (at least as a broadbrush explanation for why people embrace conservativism). Thus, correlations in the range of $r=$ .35 to .65 may be needed to constitute good evidence. Null or negative correlations, by contrast, would imply the need for a more nuanced explanatory framework than that presently provided (e.g., Costello et al., 2021; Tetlock, 1986; Zmigrod, 2021).

\section{Are People Ideological?}

Among political philosophers, conservatism and liberalism refer to complex systems of analyses regarding sociopolitical arrangements, underwritten by core assumptions about the world, and prescriptive rules and norms for political actions derived from said systems (e.g., Heywood, 2017). At this level of analysis, conservatism is often identified with the classic 
Burkean notion that present institutions and practices hold practical wisdom and value for reasons that are difficult to identify in light of society's complexity, and as such efforts to improve society should be slow and incremental. Many hypothesized mechanisms underlying the relation between political ideology and psychological needs seem to build on this base. For instance, it is often argued that conservatism sates a cognitive-motivational affinity for needs for safety and certainty because it offers a sense of predictability and dependability by way of its support for current social norms and hierarchies (Jost et al., 2003).

Nevertheless, the relevance of psychological characteristics to the epistemic qualities of whole-cloth belief systems is dubious. Methodologically diverse studies suggest that at most 20$30 \%$ of the public (a) interprets politics through the prism of abstract political principles, (b) can accurately describe which issue positions "go together" ideologically, and/or (c) holds stable, internally consistent policy views (e.g., Converse, 1964, 2000; Freeder et al., 2019; Kalmoe, 2020; Zaller, 1992). To give one well-known example, many American citizens who selfidentify as political conservatives prefer left-leaning economic policy preferences (Ellis \& Stimson, 2012; see also Zell \& Bornstein, 2014). Accordingly, a conceptual resonance between the tenets of philosophical conservatism and psychological needs may have little bearing on relations between needs and ideology in the general population. Although the model of the sort forwarded by Gries and colleagues might account for the beliefs of certain subcultures of educated activists (see Tetlock, 1984), there is little reason to believe everyday people would have such philosophically coherent bases for forming ideological preferences. This is not to say people never have reasons for their ideology, only that it seems more likely that these are often simple, direct reasons that apply to individual policy preferences (e.g., I am a single father so I support paid paternity leave; I am threat sensitive so I oppose gun control) and not left vs. right 
political ideology as a whole. Most of us most of the time are morselizers, not totalizers (Converse, 1964; Tetlock, 1986).

This raises an additional thought experiment. As observed by Kinder (1998), "If, in the end, the modesty and contingency of the effects of principles disappoint those who yearn for a politics of ideas, others may be surprised that ideas count at all" (p. 812; quoted in Kalmoe, 2020). Thus, how much should ideas "count" to move the needle of our theoretical perspectives? Specifically, if evidence emerges to suggest that $10 \%$ of the public holds epistemically coherent political preferences (vs. $25 \%$ vs. $50 \%$ vs. $75 \%$ ), how should this impact our confidence? Interestingly, one implication of a non-ideological majority is that most samples in political psychology will understate the relation between psychological characteristics and ideological preferences for those who are ideological. If, for example, only the $10 \%$ of individuals who are ideological demonstrate ideology-need correlations, then (a) the true effect size for these relations is likely larger than most previous studies, which are typically based on samples of predominantly non-ideological individuals, have estimated, yet (b) the elective affinities account does not explain most people. Another possibility is that even individuals who are not ideological show ideology-need correlations (e.g., those who identify as conservative, but do not understand conservative policy principles, have just as high needs for certainty and safety as those who identify as conservative and do understand conservative policy principles). This would imply that psychological needs are not related to the epistemic content of political ideologies and may instead be the product of top-down factors that lead people to symbolically align themselves with conservatism vs. liberalism.

\section{Disentangling Motivated Bias from Rationality: How Do Motives and Ideas Interact?}


In his 1920 book, The Thing, G.K. Chesteron proposed a principle that President Kennedy famously paraphrased: “Don't ever take a fence down until you know the reason why it was put up" (Miner \& Rawson, 2006). This has come to be known as Chesterton's fence, but many psychologists might describe it by another name: status-quo bias (the empirical claim that, relative to alternatives of similar expected value, a current choice/status-quo is often evaluated more positively by decision-makers). Given that conservative ideology is often conflated with preferences for the status-quo (Jost et al., 2003), status-quo bias meshes well with the notion that conservatives are more biased than liberals (Baron \& Jost, 2019; cf. Ditto et al., 2019).

Proponents of system justification might argue, for instance, that Chesterton's fence amounts to a conservative rationalizing their motivational preferences for the status-quo and institutional inertia. Yet status-quo bias in not necessarily a bias from a conservative point of view-per Chesterton's fence, institutional inertia may be rational. So, which came first, the motive or the insight (Mitchell \& Tetlock, 2009)? The boundary between reasons and rationalizations is much fuzzier than the electoral-affinities model would seem to allow.

Attempts to resolve this question are fraught with circularity and indeterminacy. Consider the example of free-market economic ideology. If one believes that economic prosperity is facilitated by incentives for hard work and risk-taking (which invariably result in economic inequality), this belief might be taken as evidence of system justification motives (i.e., the belief that the wealthy are rewarded for merit). Yet, by the same token, the belief might be taken as evidence that one understands a basic principle of economics. Are conservatives justifying their motivated irrationality? Or are they being rational? And who presumes to make this determination? 
Arbitrating between these competing possibilities requires engaging with evidence with the potential to change our minds. Thus, we pose a final thought experiment: What would it take for proponents of elective affinities not to view conservatives' policy preferences as downstream consequences of the functional imperative to defend the status-quo (or other motives)? This question may be more difficult to answer than it appears, in part because the electoral affinities account posits deep-rooted psychological motivations that are inaccessible to introspection. Certainly, this might describe some of the people some of the time, but we suspect that system justification theory (and its kindred "subterranean-motivational" theories in political psychology; Mitchell \& Tetlock, 2009) veers perilously close to Popper's appraisal of psychoanalytic and Marxist theory (philosophical ancestors of system justification and elective affinities theory; Jost, 1995). Both "contain most interesting psychological suggestions, but not in a testable form" (Popper, 1963, p 38). Accordingly, we invite proponents of elective affinities and system justification theory to (a) answer our thought experiments and (b) propose thought experiments of their own rooted in falsifiable predictions that can be derived from said theories. From there, we might leverage these experiments to conduct adversarial collaborations using paradigms that both sides agree have the potential to change our minds. We venture that, if these collaborations are successfully carried out, psychological science will finally move closer to reconciling an intellectual conflict that has dragged on for well-over half a century. 


\section{References}

Adorno, T. W., Frenkel-Brunswik, E., Levinson, D. J., \& Sanford, R. N. (1950). The Authoritarian personality. New York: Harper.

Altemeyer, R. A. (1996). The authoritarian specter. Harvard University Press.

Bacon, F. (1620/1952) Novum organum. University of Chicago Press.

Baron, J., \& Jost, J. T. (2019). False equivalence: Are liberals and conservatives in the United States equally biased?. Perspectives on Psychological Science, 14, 292-303.

Bakker, B.N., Lelkes, Y., Malka, A. (in press). Rethinking the link between self-reported personality traits and political preferences. American Political Science Review.

Block, J., \& Block, J. H. (2006). Nursery school personality and political orientation two decades later. Journal of Research in Personality, 40, 734-749.

Claessens, S., Fischer, K., Chaudhuri, A., Sibley, C. G., \& Atkinson, Q. D. (2020). The dual evolutionary foundations of political ideology. Nature Human Behaviour, 1-10.

Charney, E. (2015). Liberal bias and the five-factor model. Behavioral and Brain Sciences, 38.

Clark, C. J., \& Tetlock, P. E. (2022). Adversarial collaboration: The next science reform. In C. L. Frisby, R. E. Redding, W. T. O’Donohue, \& S. O. Lilienfeld (Eds.), Political Bias in Psychology: Nature, Scope, and Solutions. New York: Springer.

Converse P. (1964). Ideology and discontent. New York: The Free Press.

Cooper, R. (2005). Thought experiments. Metaphilosophy, 36, 328-347.

Costello, T.H., Bowes, S.M., Malka, A., Baldwin, M., Tasimi, A., Lilienfeld, S.O. Thinking, left and right: Revisiting the rigidity-of-the-right hypothesis (Working paper). 
Costello, T.H., \& Lilienfeld, S.O. (2020). Social and economic political ideology consistently operate as mutual suppressors: Implications for personality, social, and political psychology. Social Psychological and Personality Science. Advance online publication.

Dennett, D. C. (2013). Intuition pumps and other tools for thinking. WW Norton \& Company.

Ditto, P. H., Liu, B. S., Clark, C. J., Wojcik, S. P., Chen, E. E., Grady, R. H., ... \& Zinger, J. F. (2019). At least bias is bipartisan: A meta-analytic comparison of partisan bias in liberals and conservatives. Perspectives on Psychological Science, 14, 273-291.

Duckitt, J., \& Sibley, C. G. (2009). A dual-process motivational model of ideology, politics, and prejudice. Psychological Inquiry, 20, 98-109.

Ellis, C., \& Stimson, J. A. (2012). Ideology in America. Cambridge University Press.

Federico, C. M., \& Malka, A. (2018). The contingent, contextual nature of the relationship between needs for security and certainty and political preferences: Evidence and implications. Political Psychology, 39, 3-48.

Feldman, S. (2013). Political ideology. In L. Huddy, D. O. Sears, \& J. S. Levy (Eds.), The Oxford handbook of political psychology (p. 591-626). Oxford University Press.

Feldman, S., \& Johnston, C. (2014). Understanding the determinants of political ideology: Implications of structural complexity. Political Psychology, 35, 337-358.

Franklin, A., Anderson, M., Brock, D., Coleman, S., Downing, J., Gruvander, A., ... \& Rice, R. (1989). Can a theory-laden observation test the theory? The British Journal for the Philosophy of Science, 40, 229-231.

Freeder, S., Lenz, G. S., \& Turney, S. (2019). The importance of knowing "what goes with what": Reinterpreting the evidence on policy attitude stability. The Journal of Politics, 81, 274-290. 
Fried, E. I. (2020). Lack of theory building and testing impedes progress in the factor and network literature. Psychological Inquiry, 31, 271-288.

Funder, D. C., \& Ozer, D. J. (2019). Evaluating effect size in psychological research: Sense and nonsense. Advances in Methods and Practices in Psychological Science, 2, 156-168.

Glass, G. V. (2015). Meta-analysis at middle age: a personal history. Research Synthesis Methods, 6, 221-231.

Gries, T., Mueller, V., \& Jost, J. (2021). The market for belief systems: A formal model of ideological choice. Psychological Inquiry.

Hamaker, E. L., Kuiper, R. M., \& Grasman, R. P. (2015). A critique of the cross-lagged panel model. Psychological Methods, 20, 102-116.

Heywood, A. (2017). Political ideologies: An introduction. Macmillan International Higher Education.

Houck, S. C., \& Conway III, L. G. (2019). Strategic communication and the integrative complexity-ideology relationship: Meta-analytic findings reveal differences between public politicians and private citizens in their use of simple rhetoric. Political Psychology, 40, 1119-1141.

Hunter, J. E., \& Schmidt, F. L. (2014). Methods of meta-analysis: Correcting Error and Bias in Research Findings (3 ${ }^{\text {nd }}$ ed.). Newbury Park, CA: Sage Publications.

Jost, J. T. (1995). Negative illusions: Conceptual clarification and psychological evidence concerning false consciousness. Political Psychology, 397-424.

Jost, J. T., Glaser, J., Kruglanski, A. W., \& Sulloway, F. J. (2003). Political conservatism as motivated social cognition. Psychological Bulletin, 129, 339-375. 
Jost, J. T., Federico, C. M., \& Napier, J. L. (2009). Political ideology: Its structure, functions, and elective affinities. Annual Review of Psychology, 60, 307-337.

Jost, J. T., Sterling, J., \& Stern, C. (2017). Getting closure on conservatism, or the politics of epistemic and existential motivation. In The Motivation-Cognition Interface: From the Lab to the Real World: A Festschrift in Honor of Arie W. Kruglanski (pp. 56-87). Taylor and Francis.

Jost, J. T., Federico, C. M., \& Napier, J. L. (2013). Political ideologies and their social psychological functions. In M. Freeden (Ed.), Oxford handbook of political ideologies (pp. 232-250). New York, NY: Oxford University Press.

Jost, J. T., Stern, C., Rule, N. O., \& Sterling, J. (2017). The politics of fear: Is there an ideological asymmetry in existential motivation? Social Cognition, 35, 324-353.

Kahneman, D. (2011). Thinking, fast and slow. Macmillan.

Kalmoe, N. P. (2020). Uses and abuses of ideology in political psychology. Political Psychology, 41, 771-793.

Kinder, D. R. (1998). Opinion and action in the realm of politics. In D. T. Gilbert, S. T. Fiske, \& G. Lindzey (Eds.), The handbook of social psychology (pp. 778-867). McGraw-Hill.

Ksiazkiewicz, A., \& Friesen, A. (2017). Genes and politics. In S.A. Peterson \& A. Somit (Eds.), Handbook of biology and politics (pp. 85-105). Edward Elgar.

Lakens, D., Scheel, A. M., \& Isager, P. M. (2018). Equivalence testing for psychological research: A tutorial. Advances in Methods and Practices in Psychological Science, 1, 259-269. 
Malka, A., Lelkes, Y., \& Holzer, N. (2017). Rethinking the rigidity of the right model: Three suboptimal methodological practices and their implications. In Politics of Social Psychology (pp. 126-146). Psychology Press.

Malka, A., \& Soto, C. J. (2015). Rigidity of the economic right? Menu-independent and menudependent influences of psychological dispositions on political attitudes. Current Directions in Psychological Science, 24, 137-142.

Meehl, P. E. (1978). Theoretical risks and tabular asterisks Sir Karl, Sir Ronald, and the slow progress in soft psychology. Journal of Consulting and Clinical Psychology, 46, 806-834.

Mellers, B., Hertwig, R., \& Kahneman, D. (2001). Do frequency representations eliminate conjunction effects? An exercise in adversarial collaboration. Psychological Science, 12, 269-275.

Miner, M., Rawson, H. (2006). The Oxford dictionary of American quotations. New York: Oxford University Press.

Mitchell, G., \& Tetlock, P.E. (2009). Disentangling reasons and rationalizations: Exploring perceived fairness in hypothetical societies. In J.T. Jost, A.C. Kay, \& H. Thorisdottir (Eds.), Social and psychological bases of ideology and system justification. New York: Oxford University Press.

Osborne, D., \& Sibley, C. G. (2020). Does Openness to Experience predict changes in conservatism? A nine-wave longitudinal investigation into the personality roots to ideology. Journal of Research in Personality, 87, 103979.

Osmundsen, M., Hendry, D.J., Lautsen, L., Smith, K.B. \& Petersen, M.B. Te Psychophysiology of political ideology: replications, reanalysis and recommendations. Preprint at PsyArXiv https://doi.org/10.31234/osf. io/49hfg (2019). 
Platt, J.R. (1964). Strong inference. Science, 146, 347-353.

Popper, K. R. (1940). What is dialectic? Mind, 49, 403-426.

Popper, K. R. (1963). Conjectures and refutations. Routledge and Kegan Paul.

Redding, R. E. (2001). Sociopolitical diversity in psychology: The case for pluralism. American Psychologist, 56, 205-215.

Reyna, C. (2018). Scale creation, use, and misuse: How politics undermines measurement. The politics of social psychology, 81-98.

Roberts, S., \& Pashler, H. (2000). How persuasive is a good fit? A comment on theory testing. Psychological Review, 107, 358-367.

Roberts, B. W., Luo, J., Briley, D. A., Chow, P. I., Su, R., \& Hill, P. L. (2017). A systematic review of personality trait change through intervention. Psychological Bulletin, 143, 117141.

Rodgers, J. L. (2010). The epistemology of mathematical and statistical modeling: A quiet methodological revolution. American Psychologist, 65, 1-12.

Sniderman, P. M., \& Tetlock, P. E. (1986). Symbolic racism: Problems of motive attribution in political analysis. Journal of Social Issues, 42, 129-150.

Stanovich, K. E., \& Toplak, M. E. (2019). The need for intellectual diversity in psychological science: Our own studies of actively open-minded thinking as a case study. Cognition, 187, 156-166.

Stieger, M., Flückiger, C., Rüegger, D., Kowatsch, T., Roberts, B. W., \& Allemand, M. (2021). Changing personality traits with the help of a digital personality change intervention. Proceedings of the National Academy of Sciences, 118. 
Tetlock, P. E. (1989). Structure and function in political belief systems. In A. R. Pratkanis, S. J. Breckler, \& A. G. Greenwald (Eds.), Attitude structure and function (pp. 129-151). Hillsdale, NJ: Erlbaum.

Tetlock, P. E. (1986). A value pluralism model of ideological reasoning. Journal of Personality and Social Psychology, 50, 819-827.

Tetlock, P. E. (1984). Cognitive style and political belief systems in the British House of Commons. Journal of Personality and Social Psychology, 46, 365-375.

Tetlock, P. E., Hannum, K. A., \& Micheletti, P. M. (1984). Stability and change in the complexity of senatorial debate: Testing the cognitive versus rhetorical style hypotheses. Journal of Personality and Social Psychology, 46, 979.

Tetlock, P. E., \& Mellers, B. A. (2011). Intelligent management of intelligence agencies: Beyond accountability ping-pong. American Psychologist, 66, 542-554.

Van Hiel, A., Onraet, E., Crowson, H. M., \& Roets, A. (2016). The relationship between rightwing attitudes and cognitive style: A comparison of self-report and behavioural measures of rigidity and intolerance of ambiguity. European Journal of Personality, 30, 523-531.

Van Hiel, A., Onraet, E., \& De Pauw, S. (2010). The relationship between social-cultural attitudes and behavioral measures of cognitive style: A meta-analytic integration of studies. Journal of Personality, 78, 1765-1800.

Wilson, G. D., \& Patterson, J. R. (1968). A new measure of conservatism. British Journal of Social and Clinical Psychology, 7, 264-269.

Zaller, J. R. (1992). The nature and origins of mass opinion. Cambridge university press.

Zell, E., \& Bernstein, M. J. (2014). You may think you're right... Young adults are more liberal than they realize. Social Psychological and Personality Science, 5, 326-333. 
Zmigrod, L. (2021). A psychology of ideology: Unpacking the psychological structure of ideological thinking. Preprint. 